\title{
THINKING GERMAN IT CONSOLIDATION TO THE END - AN APPROACH TO USER TRAINING IN THE CONTEXT OF IT CONSOLIDATION
}

\author{
Carolin Hilgers ${ }^{1}$
}

DOI: 10.24989/ocg.v.338.4

\begin{abstract}
The consolidation and centralization of the IT landscape and software is meant to gain synergy effects and cost savings. Uniform processes and IT procedures within a corporate group or administrative department prevent redundant data storage, ensure uniform data maintenance and facilitate the evaluation of this data, assist cooperation and increase transparency.
\end{abstract}

In literature, various success factors are discussed in this context. These studies all focus on the changeover process, but not on the subsequent productive operations of the IT procedures. Accordingly, the published concepts of IT consolidation in Germany, for example, contain exactly this and end at the rollout of the various projects.

But, a structured user training is essential for the long term conservation of the advantages of uniform IT procedures mentioned above. Therefore, a consolidation of the IT procedures requires also a consolidation and structuring of the associated trainings. This paper discusses the necessity of structured and continuous training programs in the context of IT consolidation. It arranges the basic characteristics of those programs und derives the requirements for systems and trainings environments to operate them.

\section{Introduction}

With "IT Strategy 2017-2021", the German federal administration has defined and specified binding interdepartmental goals and fields of action for the further development of the entire IT of the federal administration [8]. These goals and fields of action will be mainly implemented in the major project IT-Konsolidierung Bund (Federal IT Consolidation) and the associated measures from the Federal IT Framework Planning under the control of the Federal IT Council [4]. Federal IT consolidation relates to the direct federal administration and follows three lines: consolidating operations, centralizing procurement, and consolidating services.

Operational consolidation means streamlining of the IT service providers' landscape. In the future, the 96 federally owned computer centres (as of 2013) will be bundled into a service network of four IT service providers in order to successively take over the entire operation and development of basic and cross-sectional services. The IT service providers are to provide the IT services centrally as a "full service" [4].

\footnotetext{
${ }^{1}$ Federal University of Applied Administrative Sciences, Department of Finance, Gescherweg 100, D-48161 Münster, Germany; carolin.hilgers@vit-bund.de; www.vit-bund.de; www.hs-bund.de.
} 
Within the framework of procurement bundling, the procurement of hardware and software is to be concentrated in a few IT procurement offices in order to achieve a qualitative improvement in procurement [4].

The service consolidation refers to the application level. The existing range of cross-sectional, basic and infrastructure services is to be harmonized and, as far as possible, consolidated, optimized and, if necessary, expanded at one of the four IT service providers. This is to avoid double and multiple developments of IT systems with the same functional scope. The rough concept explicitly specifies some important IT applications that are to be used by all federal authorities "within the next few years". Examples include the creation of a federal cloud, the development and introduction of a basic service E-File and the consolidation of personnel administration systems [4].

The strategic management of the Federal IT Consolidation is subject to the CIO Council. The Federal Ministry of the Interior, Building and Community (FMI) is responsible for entire project management. The finalisation of the service consolidation, which also represents the finalisation of the entire project, is scheduled for December 2025 [4].

\section{Background}

When taking a closer look at the project design of Federal IT Consolidation, a few points stand out. From an organisational point of view, it is remarkable that the six sub-projects are each the responsibility of a different department and that none of the four future IT service providers is subordinate to the FMI [4]. The federal ministries are generally obliged to cooperate. In the event of differences of opinion, however, the lead ministry may not make any generally binding decisions that require the agreement of other ministries (Common Rules of Procedure of the Federal Ministries, paragraph 19 (2)). FMI, as the overall project manager, and the respective ministries responsible for the sub-projects therefore do not have the power to make decisions on their own responsibility for the entire federal administration. If the FMI's lack of control over the four future IT service providers is also taken into account, there is a significant project risk. The Bundesrechnunghof (BRH), the German supreme audit institution, criticized the structure of the Federal IT Consolidation already at the beginning of the project and called for clear regulations [5]. "For a successful Federal IT Consolidation, the federal government must design the dialogue between the departments and the decision-making processes effective and efficient." [7] However, no substantial changes to the rough concept are identifiable. The BRH has repeatedly criticised the control of the economic efficiency and the financing of the large-scale project, for example in [5] and [6].

A closer look at the consolidation of services also reveals some aspects. First, there are organizational problems. Service consolidation is being implemented under the leadership of the FMI in sub-project 6 "Joint IT of the Federal Government". This sub-project is responsible for identifying IT requirements that can be clustered and for framework planning. The Federal Information Technology Centre (ITZBund) will carry out the implementation, i.e. the development and operation of infrastructure, basic and cross-sectional services, if appropriate in cooperation with (one of) the other service providers of the service network [4]. The ITZBund is subordinate to the Federal Ministry of Finance (FMF), so that FMI has no direct authority to issue instructions to the ITZBund. Conflicts seem to be inevitable. The consolidation of the personnel management systems will serve as an example. In the future, the personnel administration system of the FMF is to be used throughout the entire direct federal administration [15]. The project group at the FMI carries out the planning and control of this task. The individual federal authorities of the various departments carry out the implementation of the individual projects. Moreover, the ITZBund will be responsible for operation 
including user support. The FMF is responsible for the content of the procedure. It is unlikely to assume that the two major ministries will be lenient towards each other.

It is also striking that the available concepts only refer to the changeover process. From kick-off to rollout, all functional, technical and change management issues are considered. The phases of operation, support and maintenance, which are part of the standard life cycle process of software [12], are not taken into account.

\section{Question}

The last point will be in focus of this paper. I question if only the construction of the changeover process of IT consolidation projects are important for successful IT consolidation. Do we ignore important success factors for IT consolidation, which are assigned to the phases after the rollout of a consolidation project, e.g. the various user groups, (the organisation of) user training or user support?

From all these possibilities, I will focus on user training. I will show that a structured and consolidated concept for user training is an important factor for the achievement of the objectives of consolidation projects in general and Federal IT Consolidation in particular. After an evaluation of literature, I discuss the objectives of consolidation, centralisation and standardisation projects. Subsequently, it is explained to what extent further training programs contribute to the achievement of these objectives. A proposal for the consolidation of the necessary IT further training including a possible infrastructure for training environments is outlined.

\section{Evaluation of literature on IT consolidation}

There is a lot of literature on IT consolidation with different focusses. [10] analysed the literature in 2010 and identified two different approaches of the available studies. Group 1 focuses on cost goals, group 2 on functional goals. Additionally, I looked for younger studies on IT consolidation with egovernment relevance. But there was little success, only a few authors deal with IT consolidation in context of e-government - [1], [11], [17]. These papers mention cost goals as well as functional goals of IT consolidation; there is no special focus for one of them. The different individual objectives are summarized in table 1 .

However, both the studies analysed by [10] and the other three papers refer only to the changeover process of IT consolidation. That is why I also took literature on requirements for IT processes in administration - [16], [23] - into account.

\section{The objectives of the consolidation projects}

The Federal IT Consolidation has various objectives [4]:

(1) Guaranteeing IT security in an increasingly complex environment,

(2) Maintaining sovereignty and control over its own IT,

(3) Sustainability by enabling the adaptation of technical innovations,

(4) Ensuring "efficient, economic, stable and sustainable" operation,

(5) The attractiveness as an employer for IT specialists and

(6) Protecting of the data of the Federal Administration and its safeguarding against misuse. 
These goals are based on the federal IT strategy that defines strategic goals for demand-oriented support of administrative tasks [8]:

- $\quad$ Effectiveness and quality,

- Digital administration,

- Sustainability and openness for innovation,

- Information security and data security,

- $\quad$ Attractiveness as an employer,

- $\quad$ Economic efficiency and cost effectiveness,

- $\quad$ Inclusion and accessibility

- Environmental sustainability,

- $\quad$ Cooperation, and

- $\quad$ Ability to control and manage.

These objectives coincide with the objectives mentioned in the literature on IT consolidation. Table 1 summarizes the literature evaluation and combines it with the objectives of the Federal IT Consolidation. The crosses indicate a target match.

\begin{tabular}{|l|c|c|c|c|c|c|}
\hline & obj. (1) & obj. (2) & obj. (3) & obj. (4) & obj. (5) & obj. (6) \\
\hline $\begin{array}{l}\text { Efficient use of capacities } \\
\text { (infrastructure, hardware) } \\
\text { [10] [11] [16] }\end{array}$ & & & $\mathrm{x}$ & $\mathrm{x}$ & & \\
\hline $\begin{array}{l}\text { Cost savings, easier budget control } \\
\text { and management [1] [10] [16] }\end{array}$ & & $\mathrm{x}$ & & $\mathrm{x}$ & & \\
\hline $\begin{array}{l}\text { Economies of scale (staff, } \\
\text { procurement) [1] [11] [16] }\end{array}$ & & $\mathrm{x}$ & & $\mathrm{x}$ & $\mathrm{x}$ & \\
\hline $\begin{array}{l}\text { Greater security, reduced risks } \\
\text { [1] [10] }\end{array}$ & $\mathrm{x}$ & $\mathrm{x}$ & $\mathrm{x}$ & $\mathrm{x}$ & $\mathrm{x}$ & $\mathrm{x}$ \\
\hline $\begin{array}{l}\text { Standardisation of processes } \\
\text { (professionalisation of employees, } \\
\text { dissemination of best practices) } \\
\text { [10] [11] [17] [23] }\end{array}$ & $\mathrm{x}$ & $\mathrm{x}$ & $\mathrm{x}$ & $\mathrm{x}$ & $\mathrm{x}$ & \\
\hline $\begin{array}{l}\text { Improved control over IT, higher } \\
\text { compliance [10] [17] }\end{array}$ & & $\mathrm{x}$ & & & $\mathrm{x}$ & $\mathrm{x}$ \\
\hline $\begin{array}{l}\text { Provision of information also } \\
\text { across departments }\end{array}$ & & $\mathrm{x}$ & & & $\mathrm{x}$ & \\
[1] [11] [16] [17] & $\mathrm{x}$ & $\mathrm{x}$ & $\mathrm{x}$ & $\mathrm{x}$ & $\mathrm{x}$ & $\mathrm{x}$ \\
\hline $\begin{array}{l}\text { Extended (digital) provision of } \\
\text { services [1] }\end{array}$ & & $\mathrm{x}$ & $\mathrm{x}$ & $\mathrm{x}$ & \\
\hline $\begin{array}{l}\text { Avoidance of redundant data } \\
\text { [17] [23] }\end{array}$ & & $\mathrm{x}$ & $\mathrm{x}$ & $\mathrm{x}$ \\
\hline $\begin{array}{l}\text { Minimization of interfaces } \\
\text { [16] [23] }\end{array}$ & & & & & \\
\hline
\end{tabular}

Table 1: Objectives of consolidation programs

The table shows that the objectives of Federal IT Consolidation are largely in line with the objectives in the literature. In addition, the objectives of the Federal IT Consolidation belong to both group 1 (cost objectives) and group 2 (functional objectives). 


\section{The contribution of further education to the achievement of objectives}

According to the Classification of Learning Activities, there are formal education, non-formal education, and informal learning [9]. Formal education covers all regular educational activities that end with a formal qualification and last at least six months - e.g. attendance at (high) school or university. Non-formal education is all learning activities that do not belong to formal education, but have an organised teaching/learning arrangement. These include continuing vocational training in enterprises, individual vocational training and non-vocational training. Informal learning involves all purposeful, non-random learning activities that cannot be assigned to the first two groups [2]. In the context of Federal IT consolidation, we focus on continuing vocational training to adapt to new standardised IT procedures, ergo non-formal education.

The change management activities of the individual consolidation projects include further training to give the necessary knowledge of the new application to the current specialists. This is required in accordance with Nos. 8 and 14 of the Guidelines for the Use of Information Technology in the Federal Administration (IT Guidelines). In accordance with No. 14 (1) of the IT Guidelines, it is necessary to adapt the IT further training catalogues of the federal training institutions in line with (new) requirements. Since the initial training courses for the introduction of new applications are by definition one-off training activities and, according to No. 14 (2) IT Guidelines, it is also permissible for external providers to cover the demand, it is possible to deny that these conversion training courses are anchored in the training catalogues of the federal training institutions. But, there will be user fluctuation in the future. These new users also need an instruction to this application, so called fluctuation training. These fluctuation trainings are part of the operation phase in the life cycle of software and thus subordinate to the rollout. The IT Guidelines are also relevant here, so training on new consolidated IT services must be included in the training catalogues. The rough concept of the Federal IT Consolidation does not contain any plans for this [4], even though it is possible to derive arguments for structured and consolidated further trainings for IT, away from legal rules.

However, the literature on this subject is not very fruitful, since the focus of the available studies on IT consolidation and centralisation is on the changeover process, similar to the concepts of the German Federal Government, and the phases after the rollout are not taken into account. There are only a few studies on critical success factors for IT projects that explicitly list user training and education [21] [23]. However, it is not clear whether this refers to training within the scope of the rollout (so-called changeover training) and/or training for future users (fluctuation training). Therefore, based on the objectives of Federal IT Consolidation, it should be argued to what extent structured and consolidated further training can contribute to the goals of consolidation projects.

\subsection{Objective (1): IT Security}

According to ISO 27000:2018 [13], IT security is the guarantee of the confidentiality of information as well as the integrity and availability of the systems and the information contained therein. The corresponding ISO 27002:2013, Code of Practice for Information Security Management, describes best practices for IT security management [14]. Section 7 deals with human resource security and Section 7.2 explicitly deals with necessary training programs in the operational phase of software. Further training of employees is thus an essential measure for achieving the goal of IT security. Employees who have been well trained in using an application are aware of the relevance of the information contained and their own input. They understand the processes and interfaces and can assess the impact of their system activities. They understand the implemented security precautions (password rules, screen locks, etc.), are familiar with them and apply them. 


\subsection{Objective (2): Control and sovereignty over own IT and objective (3): Sustainability}

These two objectives are summarized here in one section because there is no influence by the users for achieving these goals. However, vocational training can help in adapting the qualifications of employees to new technologies and strengthening their innovative ability [20].

\subsection{Objective (4): Efficient, economic, stable (and sustainable) operation}

This goal is significantly influenced not only by the hardware and the administrative personnel, but also by the users. Employees who are well trained in the handling of an application can use the existing functions of the software professionally and appropriately. If there is a change of employer within the federal administration, no training is necessary, since all direct federal authorities will use the same applications in future. The frequency of errors is reduced and downstream processes can be carried out more reliably. There will be better data quality and evaluations become more accurate, so that decisions will base on better information. If a ministry and its subordinate authorities use the same application, interdepartmental statistics can be produced directly by the ministry. This eliminates the need for data collection at the lower levels as well as consolidation efforts within the ministry. The benefits of this application increase. Especially for central evaluations and statistics, it is essential that all users execute the processes and functions in the same way in order to obtain reliable and comparable data sets. Only standardised training measures can ensure this. IT consolidation therefore also requires training consolidation. Good, standardised user trainings thus contribute to the stability, performance and cost-effectiveness of an application.

\subsection{Objective (5): Attractiveness as an employer for IT specialists}

Public administration is currently not attractive for future IT professionals [22]. It can be assumed that a modern IT landscape can increase attractiveness. However, there is no evidence of this. Development opportunities such as established professional training can be a decision criterion for an employer [22]. From the perspective of companies providing continuing vocational training, the provision of continuing vocational training can also increase the attractiveness of the company [20]. [19] show, for example, that there is a significant correlation. The German Federal Government also identifies this point, but focuses on the recruitment of skilled workers [8]. However, this view neglects IT specialists already employed in the federal administration. Internal company training offers them development opportunities and shows an appreciation of their work. The labour market for IT specialists is a supplier market, and dissatisfied highly qualified employees have many alternatives [3].

\subsection{Objective (6): Data Security}

Data protection and protection of data against misuse are often mentioned in the same breath as IT security. While IT security focuses on the protection of data and information against unauthorized access, loss or unintentional modification, data security focuses on the persons concerned. The EU General Data Protection Regulation stipulates that the storage and processing of personal data must be carried out in accordance with the principles of legality, purpose limitation, data minimization, storage limitation, integrity and confidentiality, and accountability. The responsibility for compliance with these principles lies with the responsible body of an application. However, the users of the application implement these principles. This requires a sufficient awareness of the users, which can be achieved by high-quality training and further education. In this way, users can understand the implemented protective mechanisms and apply them. 


\section{Suggestion for training consolidation}

The above arguments lead to the conclusion that a structured and standardised further training of employees even after the start of operations (so-called fluctuation training) contributes essentially to the achievement of the objectives of the Federal IT Consolidation. Above all, the argumentation for objective (4) shows that without consolidated user trainings, the goals of Federal IT Consolidation could be missed.

Structured and consolidated user trainings should be characterised by the following features:

- Uniform content for all participants of all departments,

- Well-structured case studies with clear instructions and

- $\quad$ Practical, independent exercises in a representative exercise environment.

The user trainings can be carried out equally as face-to-face events or e-learning.

To reach these requirements for each application, a central organisation with guideline competence is required (responsible for training - RFT). It determines the training formats and their contents for all users in any department and provides the teaching materials. In particular, this includes an exercise environment with representative practice data and the case studies. Since all trainings access the same training system, the administration of the user trainings should also be centralized, depending on the system characteristics. The RFT does not have to be identical with the organisation responsible for administration. Any qualified trainers should be able to teach user-training modules prepared in this way. The extent of decentralization is to be determined by means of a profitability analysis.

For the user training of an application, there must be direct and complete access to an associated training environment. In order to be able to train normal users and advanced key users as well as personnel entrusted with customizing and administration tasks, in addition to a rather 'rigid' teaching environment for application-oriented training, the ability to teach customizing or system settings in a kind of virtual 'laboratory environment' in a corresponding functional context is required. This can even be realised in the operating process of this teaching environment if the RFT is responsible for it. The operator of the application would have to provide a virtualisation of the training environment, and RFT will administer this VM (update, upgrades, master data maintenance etc.). The execution of the trainings thus becomes independent of location and service provider. The necessary direct services during the courses, e.g. in the form of a hotline, can be optimally coordinated within RFT. It is possible to scale the number of parallel courses so that course administration is simplified.

A look at the continuing vocational training of employees in the German federal administration reveals a very heterogeneous picture. Each department is responsible for regulating the continuing vocational training of employees. As can be seen from the websites of the several departments, internal training institutions are established in a few departments, but not in most of them. The Federal Academy of Public Administration (BAköV) is a provider of further training for all employees of the German federal administration. However, this institution is not an educational institution with its own trainers, but offers continuing education courses with external trainers. The BAköV does not offer further training on IT applications (usage, administration etc.). The few departmental further education institutions employ full-time trainers and offer training on departmental applications and other IT training, e.g. on Microsoft Office applications or Windows administration. Due to the small number of in-house training institutions, external providers on the open market provide a large part of the in-company training. 
A standardised and consolidated user training according to the above criteria for the IT services affected by the Federal IT Consolidation will not be possible without organisational restructuring of the federal administration. Two basic scenarios are conceivable.

On the one hand, you can think of a consolidation of user training for each application. Then you need to name and set up a RFT for each. It is obvious to assign this to the authority or institution that is responsible for the application. If this authority or institution does not have any further training tasks under the current legislation, organisational regulations must be adapted. Thus, an application is offered from a single source. Experiences from user support can flow into the training development and vice versa. A synchronization of training case studies and test cases is possible, which reduces test efforts after updates and upgrades. The employees of RFT train the trainers in the usage of the application. A disadvantage is that comparisons and experience transfer from one application to another are made more difficult in this constellation. Possible parallels in terms of content or training environments cannot be used. The execution of the centrally provided training formats can be organised by each department itself. The full-time trainers of the departmental education institutions can conduct the training courses in the same way as non full-time trainers in the other departments. Outsourcing to external providers of further education can also be considered. A central institution is recommended for the administration of the respective user trainings. In order to achieve economies of scale, this institution can also administer the user trainings of all applications.

On the other hand, you can think of establishing a central education institution (CEI) as RFT for all consolidated IT services, which would cooperate closely with the respective responsible departments. This CEI should also take over the administration of the user trainings. The disadvantages mentioned above are obsolete. Close cooperation between the CEI and the responsible department can achieve the synergy effects mentioned between further training and application support or testing. The complete execution of all user trainings with own full-time instructors by the CEI makes sense, but is not necessary. A combined execution by the CEI and departmental education institutions is also conceivable. The locations for implementation are to be determined according to cost-effectiveness criteria. You can also think of integration of other IT training courses that are in great demand, such as those on Microsoft or SAP products.

In both cases, in addition to organizational restructuring, an increase in personnel is also necessary.

\section{Conclusion}

In Germany, there is currently no special IT service that is used across departments. The question of interdepartmental user trainings simply has not arisen so far. The Federal IT Consolidation changes this.

The concepts for service consolidation within the framework of the Federal IT Consolidation end with the rollout of the application to be consolidated. The training of future users, so-called fluctuation training, is not addressed. The previous literature on the subject of IT consolidation has not dealt with this topic either.

Using the example of Federal IT Consolidation, the paper shows that user trainings contribute to achieving the objectives of IT consolidation. The arguments lead to the conclusion that even standardised and consolidated user training is necessary to fully achieve all objectives and realise the benefits of IT consolidation. A short otline of the design of a training environment is presented. In 
addition, two scenarios for a consolidation of user trainings in the German federal administration are outlined.

The scenarios presented do not yet take into account the individual IT services to be consolidated. The type of software, its degree of specialisation (standard software vs. in-house development) and other characteristics must be considered in order to be able to deduce with certainty, for example, whether internal user training or the use of external training providers is more economical.

\section{Literature}

[1] BIDDINGER, N., A Primer on IT Consolidation, in: Government Finance Review, Vol. 3, Iss. 5, pp. 34-38.

[2] BILGER, F., BEHRINGER, F. and KUPER, H., Einführung, in: F. Bilger, D. Gnahs, J. Hartmann \& H. Kuper (Hrsg.): Weiterbildungsverhalten in Deutschland - Resultate des Adult Education Survey 2012, Bielefeld 2013, pp. 13-23.

[3] BUNDESAGENTUR FÜR ARBEIT, IT-Fachleute, in: Berichte: Blickpunkt Arbeitsmarkt April 2019.

[4] BUNDESKABINETT, Grobkonzept zur IT-Konsolidierung Bund, Berlin 2015.

[5] BUNDESRECHNUNGSHOF, Bericht an den Haushaltsausschuss des Deutschen Bundestages nach§ 88 Abs. 2 BHO: IT-Konsolidierung Bund, Bonn 2015.

[6] BUNDESRECHNUNGSHOF, Abschließende Mitteilung an das Bundesministerium des Innern, für Bau und Heimatüber die Prüfung „Elektronische Aktenführung und Dokumentenmanagementsysteme in der Bundesverwaltung“, Bonn 2018.

[7] BUNDESRECHNUNGSHOF, Jahresbericht 2018, Bonn 2018.

[8] DER BUNDESBEAUFTRAGTE DER BUNDESREGIERUNG FÜR INFORMATIONSTECHNIK, IT-Strategie der Bundesverwaltung 2017 - 2021, Berlin 2017.

[9] EUROSTAT, Classification of Learning Activities (CLA) - Manual, Luxembourg 2016.

[10] FRANKE, U., HOLSCHKE, O., BUSCHLE, M., NÄRMAN, P. and RAKE-REVELANT, J., IT consolidation - an optimization approach, in: 2010 14th IEEE International Enterprise Distributed Object Computing Conference Workshops. IEEE 2010, pp. 21-26.

[11] GHIA, A., Capturing value through IT consolidation and shared services, in: McKinsey on Government, Autumn 2011, pp. 18-23.

[12] ISO, ISO/IEC/IEEE 12207:2017.

[13] ISO, ISO 27000:2018.

[14] IT-RAT, Beschluss Nr. 2016/4. 
[15] KARICH, C., SENF, C. and ZIMMER, W., Der Schlüssel heißt Interoperabilität, in: H. Krallmann, A. Zapp (Hrsg.), Bausteine einer vernetzten Verwaltung, Erich Schmidt Verlag, Berlin 2012, pp. 99-129.

[16] LAUTENSCHLAGER, J., (2012), Fachverfahren 2.0, in: H. Krallmann, A. Zapp (Hrsg.), Bausteine einer vernetzten Verwaltung, Erich Schmidt Verlag, Berlin 2012, pp. 339-348.

[17] MARKUS, L., BUI, Q., JACOBSON, D. D., MENTZER, K. and LISEIN, O., It Centralizaton And Enterprise-Wide It Capabilities And Outcomes: A Public Sector Study, ECIS Completed Research, Paper 211 (2013).

[18] MOHR, S., TROLTSCH, K. and GERHARDS, C., Der Kampf um Köpfe. Verbessern Betriebe durch Weiterbildung ihre Attraktivität als Arbeitgeber?, in: REPORT, Zeitschrift für Weiterbildungsforschung 03/2013, pp. 37-47.

[19] SEYDA, S. and PLACKE, B., Die neunte IW-Weiterbildungserhebung: Kosten und Nutzen betrieblicher Weiterbildung, IW-Trends -Vierteljahresschrift zur empirischen Wirtschaftsforschung, Institut der deutschen Wirtschaft, Köln 2017, Vol. 44, Iss. 4, pp. 1-19.

[20] SUDHAKAR, G. P., A model of critical success factors for software projects, in: Journal of Enterprise Information Management, Vol. 25, Iss. 6, pp. 537 - 558.

[21] TIERSCH, K., BLANK, T., ZEPIC, R. and KRCMAR, H., Arbeitgeber(un)attraktivität der öffentlichen Verwaltung für IT-Nachwuchskräfte, in: Verwaltung \& Management, Vol. 25., Iss. 1, pp. 28-36.

[22] WONG, B. and TEIN, D., Critical success factors for ERP projects, in: Australian Project Manager, Vol. 24, Iss. 1, pp. 28-31.

[23] ZIEMANN, J., Architecture of Interoperable Information Systems, in: H. Krallmann, A. Zapp (Hrsg.), Bausteine einer vernetzten Verwaltung. Erich Schmidt Verlag, Berlin 2012, pp. 165187. 